\title{
Evidencias metalúrgicas de fundición de cobre en el sitio formativo tardío de Ramaditas, quebrada de Guatacondo, Provincia de Iquique, Chile
}

Gray Graffam $^{1}$, Alvaro Carevic $^{2}$ Y Mario Rivera $^{3}$

\author{
RESUMEN
}

En la actualidad los recursos cupríferos de la Puna de Atacama atraen la atención de iniciativas mineras internacionales, donde millones de dólares se invierten en la extracción minera de uno de los recursos más ricos del mundo. Los esfuerzos prehispánicos para extraer estos minerales se han hecho evidentes a través del registro arqueológico regional. Sitios con hornos, escoria y molienda se han registrado desde el Período Formativo Tardío al Inka. Los sitios más tardios han recibido mayor atención, mientras que se sabe poco de evidencias más antiguas o formativas. En este sentido las evidencias del sitio Ramaditas son significativas en cuanto presentan la primera indicación concreta de una fundición de cobre en la región atacameña durante el Formativo Tardío del norte de Chile (500 AC-300 DC). Los resultados logrados aquí son los más tempranos de la región y proveen una base sólida para comprender la naturaleza de estos avances antes de la incorporación de la región al Estado Tiwanaku en tiempos más tardíos, como también la naturaleza de uno de los focos metalúrgicos más tempranos del Area Centro Sur Andina.

\begin{abstract}
Today, the copper ores of Atacama attract the continued attention of international mining efforts, where millions of dollars are spent in the anual extraction of ore from one of the world's richest sources. Pre-Hispanic efforts lo tap these ores are evident in the archacological record of the region. Sites with furnace, slag, and crushed ore are seen throughout the region, spanning from the Late Formative Period thougth the Inka Period. Of these, the later sites have received the most attention to date, although much more waits to be done. The archaeological evidence from Ramaditas is significant in that it is the first firm indication of copper smelting in the Atacama region itself during the Late Formative Period of Northern Chile (500 BC to AD 300). The results provided here are the earliest for the región so far, and they provide a firm foundation for understanding the nature of these efforts prior to the incorporation of the region within the Tiwanaku State of later times, as well as the nature of early melallurgy in the South Central Andes in general.
\end{abstract}

\footnotetext{
Universidad Trent, Peterborough, CANADA.

Universidad Arturo Prat, Iquique, CHILE.

Museo Field de Historia Natural, Chicago, ESTADOS UNIDOS.
}

\section{Introducción}

Nuestro objetivo central es investigar y evaluar las evidencias de la producción de metal (cobre) en el Desierto de Atacama, durante el Período Formativo Tardío, en el sitio arqueológico de Ramaditas $(9 \mathrm{~km}$ al oeste de la aldea de Guatacondo, hacia la Pampa del Tamarugal). Este estudio forma parte de una investigación sobre patrones de asentamiento y uso de recursos naturales en el Desierto de Atacama. A ésta, se agrega el estudio de metalurgia y ciencia de materiales con los correspondientes análisis de escoria, trozos de minerales, y la interpretación del metal como sistema de fundición prehispánica utilizada en la región. En este trabajo presentamos los resultados más relevantes efectuados durante julio de 1991 y junio de 1993 de este estudio de metalurgia, basado en la ciencia de materiales (Graffam Ms).

La fundición de minerales y la extracción de metales tienen una larga historia en el Desierto de Atacama, y específicamente en el norte de Chile, es así como este sitio representa, actualmente, la primera evidencia de fundición de cobre en la región durante el Período Formativo Tardío (500 AC a 300 DC). Este estudio viene a complementar la información sobre artefactos metálicos en contextos arqueológicos de la región (Boman 1908; Nordenskiöld 1921; Latcham 1936; Kjerrmann 1944; Pedersen 1952; Irribarren 1974; Alvarez 1981; Mayer 1986; Núñez 1987; Muñoz 1989), además está de acuerdo con los modelos de comercio y movilidad complementaria (Núñez 1962; Núnez y Dillehay 1978; Dillehay y Núñez 1980; Núñez 1988; Dransart 1991; y otros) y con la literatura publicada acerca del desarrollo económico prehispánico del Norte Grande chileno (Rivera et al. 1974; Núñez et al. 1975; Rivera 1976; Núñez y Moragas 1977; Núñez 1982; Santoro 1982, Dauelsberg 1985; Castillo 1986; Muñoz 1989; Núñez 1989; Niemeyer et al. 1989; Rivera 1991; y otros), y también con el tema de metalurgia en los Andes Centro Sur en general (Petersen 1970; Benson 1979; González 1979; 
Latcham 1979; Latcham 1980; Latcham 1986; Rodríguez 1986; González 1992).

\section{Ubicación y descripción del sitio}

Ramaditas es una pequeña aldea ubicada a $9 \mathrm{~km}$ al oeste del sitio arqueológico aldea de Guatacondo dentro del margen de la Pampa del Tamarugal aproximadamente a S $21^{\circ} 0$ ' $10^{\prime \prime}$ y O 69 $21^{\circ}$ '30" (Figuras 1 y 2). El sitio fue ubicado y sucintamente mencionado por Mostny, nominándose G-2 en la prospección de la quebrada de Guatacondo (Mostny 1970, 1980; Meighan 1980).

El sitio es de una sola composición como una aldea (fue utilizado también como un campamento en épocas más tardías, pero su ocupación como aldea se desarrolla durante el Período Formativo Tardío). De acuerdo a las evidencias superficiales se puede apreciar que sus ruinas están agrupadas en tres recintos que se ubican en la planicie de la Pampa del Tamarugal (adyacente) a la antigua quebrada de Guatacondo (Figuras 2 y 3 ). Los tres recintos no son tan extensos y se sitúan en un área aproximada de 3 ha.

De los tres recintos, el más importante es el que se encuentra en el extremo sur del sitio, cerca de la quebrada. Este recinto (1) es de forma circular con aproximadamente $30 \mathrm{~m}$ de diámetro, sus murallas alcanzan una altura de $1.60 \mathrm{~m}$ del suelo (Figura 4). Este recinto está caracterizado por dos estructuras circulares que se anexan a las murallas externas con divisiones al mismo tiempo internas que denotan un uso del espacio en especial. El recinto 2 difiere del recinto 1 , ya que el primero posee estructuras circulares aglutinadas y distribuidas en torno a la plaza central. La plaza misma alcanza un diámetro de $15 \mathrm{~m}$. La construcción de estos muros fue realizada esencialmente con bloques de caliche. El recinto más grande de los tres está ubicado más hacia el norte (recinto 3). Es un recinto grande, formado por una serie de estructuras circulares aglutinadas, con dimensiones aproximadas de 28 x $68 \mathrm{~m}$. Hacia el extremo este se encuentra una plaza circular con varias estructuras anexadas. Hacia el oeste hay un grupo de estructuras que están distribuidas de manera tal que no conducen a ningún acceso o espacio público. En el área de superficie de este recinto hay ruinas de hornos con escorias, minerales, y evidencias de fuego. Estos indicadores tienen una relación directa con el uso de la zona, después de la ocupación original de este recinto.

\section{Contexto metalúrgico}

En los aledaños y casi inmediatamente al lado de Ramaditas existen evidencias de por lo menos doce sitios donde se produjo fundición. Esta evidencia se manifiesta por una serie de hornos casi totalmente destruidos, escorias, trozos de minerales, y otros restos. Los hornos en ruinas tienen formas circulares, construidos en bloques de piedra y los de caliche (los dos cubiertos de escorias) con un diámetro aproximado de 75 a $90 \mathrm{~cm}$. Los bloques de piedra de arenisca fueron ubicados en las bases de los hornos, por su capacidad refractaria al calor, y los de caliche, que también fueron utilizados en la construcción de los hornos, en las secciones superiores de los hornos. Como no se encuentran evidencias de sopletes en el área, estos hornos utilizaron la corriente de aire natural para su funcionamiento. Este sistema seguramente fue muy parecido al sistema de huayras, que los españoles descubrieron a su llegada y que incluso se siguieron utilizando en épocas históricas (Pedersen 1971; Lechtman 1976). En las superficies de los bloques de piedra que configuraban las paredes de los hornos se encuentran trozos de escoria que analizados por fluorescencia de rayos X (ver más adelante) demuestran que estos hornos fueron muy adecuados para producir fluidez a/o sobre los $1100^{\circ} \mathrm{C}$. Los elementos metálicos en esas muestras tienen un perfil que se encontró en otras escorias conocidas de fundición, las que tuvieron una temperatura de fluidez de $1250^{\circ}$ (Rehder Ms); esta observación está de acuerdo con la inspección visual de las superficies de las escorias que apoya la interpretación de fluidez (Rehder Ms; Graffam Ms). Esto ha revelado, sin dudas, que era producto de una fundición de cobre. De acuerdo a las evidencias de trozos de mineral encontrados en las cercanías de las ruinas de los hornos, y por el resultado de los análisis de las escorias (ver más adelante), se puede inferir que estos hornos fueron utilizados para fundir minerales mediante el sistema de reducción. Este indicador se manifiesta por los trozos de mineral encontrados, tales como el brochantita y antlerita, los cuales formaron parte de la carga reducida que se fundió en los hornos. La ubicación de estos hornos cerca de Ramaditas está dada por la disponibilidad de maderas que existían en el lugar, tales como tamarugo y algarrobo. Asimismo, la disponibilidad de piedras areniscas y caliche en el lugar permitió la construcción de hornos en este sitio. Es interesante destacar, además, que tanto el traslado de maderas (o carbón) para combustible, 
EVIDENCIAS METALURGICAS DE FUNDICION DE COBRE EN EL SITIO FORMATIVO TARDIO...

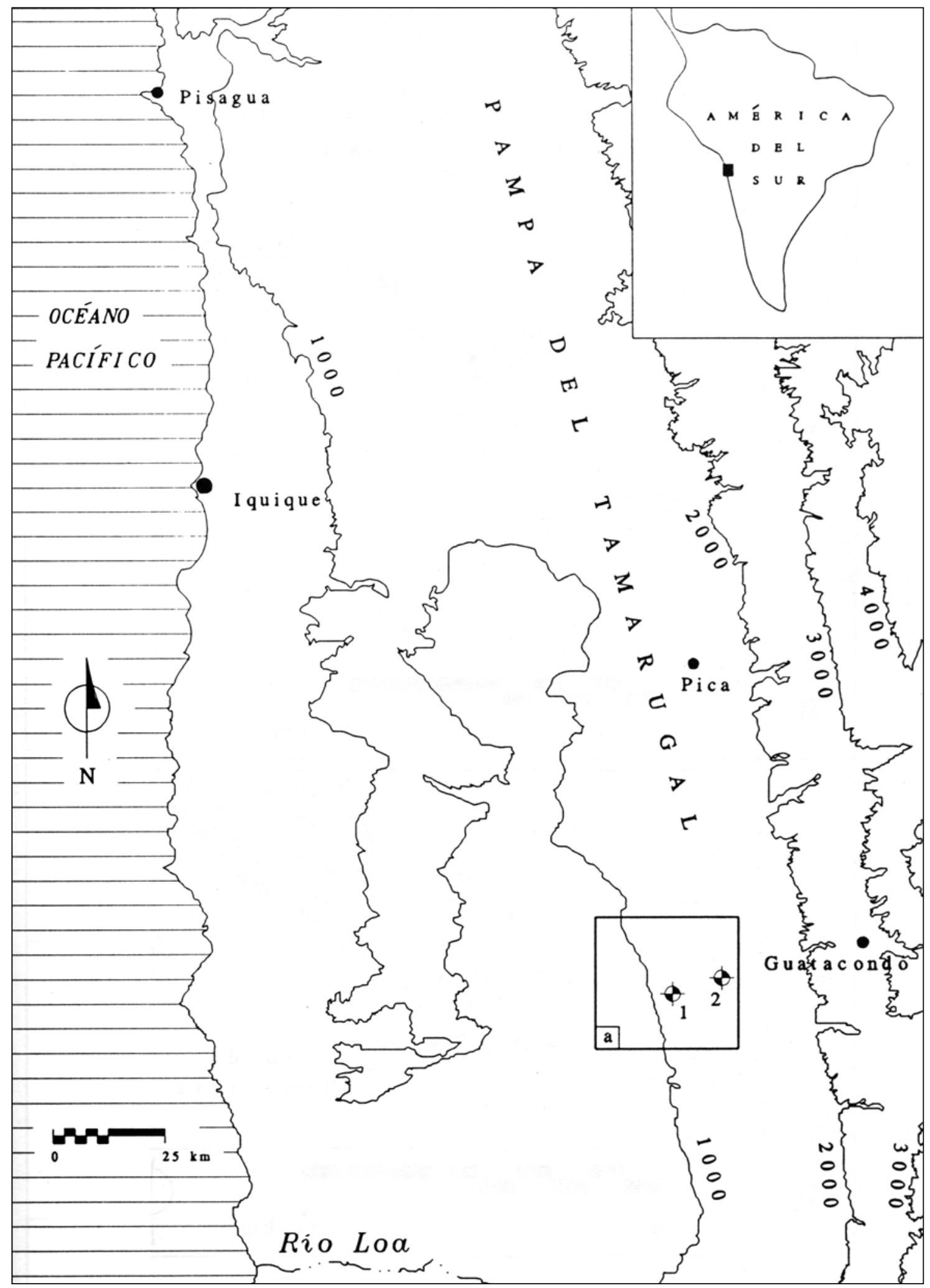

Figura 1. Ubicación del sitio de Ramaditas (1) y la aldea de Guatacondo (2) en la II Región, Chile. 

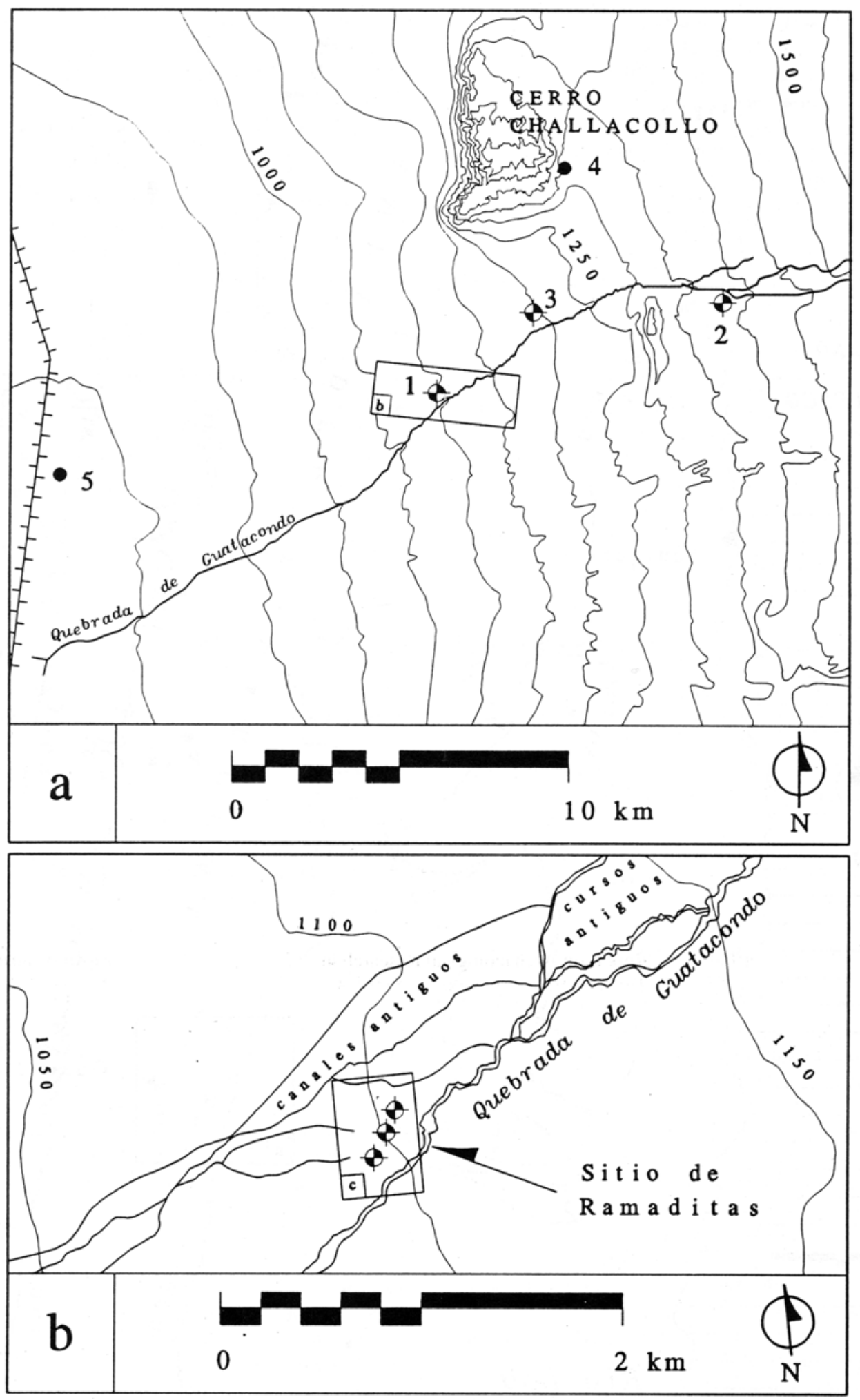

Figura 2. Ubicación del sitio Ramaditas (1), la aldea de Guatacondo (2), la aldea G-7 de Mostny (3), la Mina Chacacollo (4, histórica), y la Estación Ramaditas (5, histórica). 
EVIDENCIAS METALURGICAS DE FUNDICION DE COBRE EN EL SITIO FORMATIVO TARDIO...

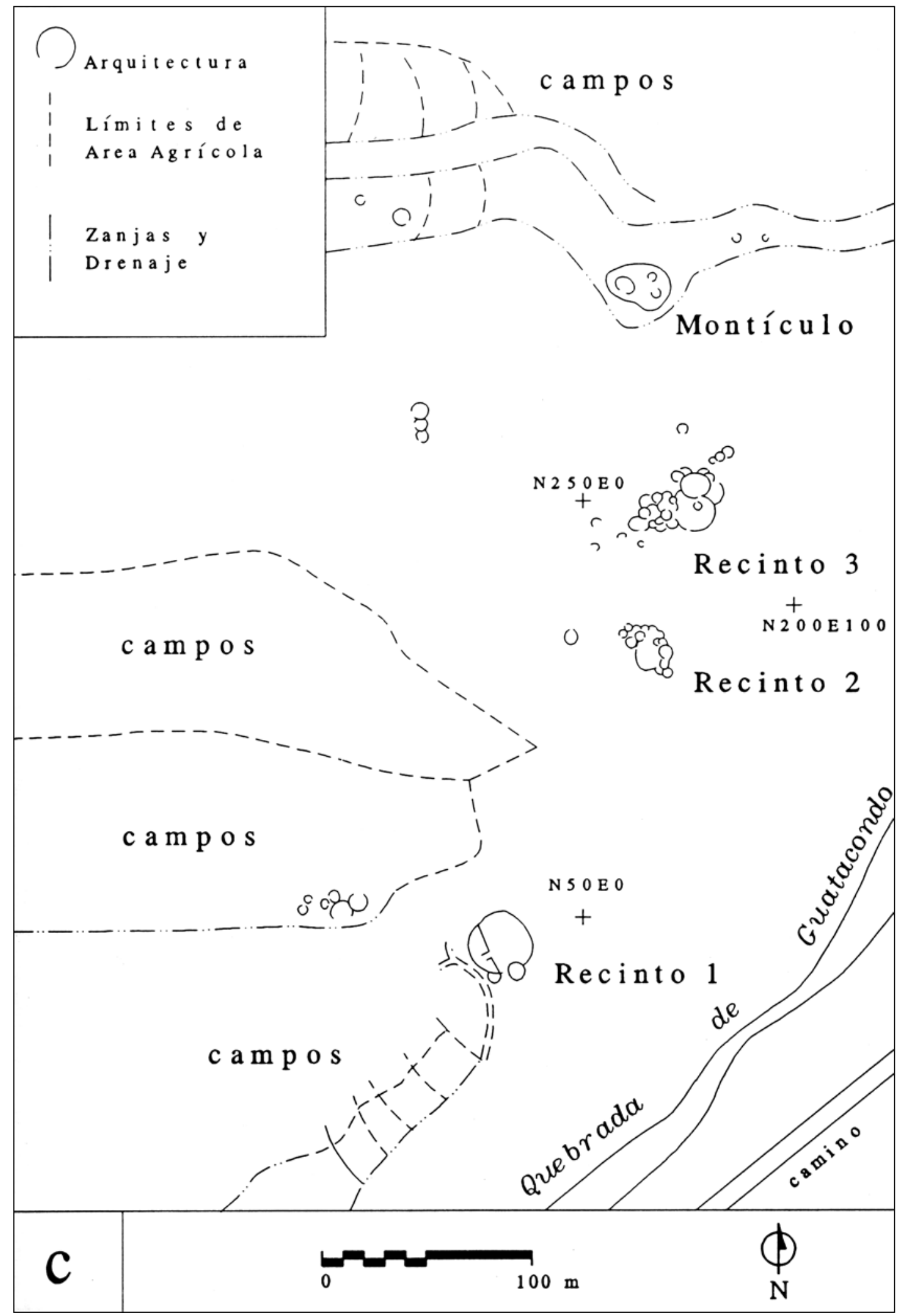

Figura 3. Mapa del sitio Ramaditas. 


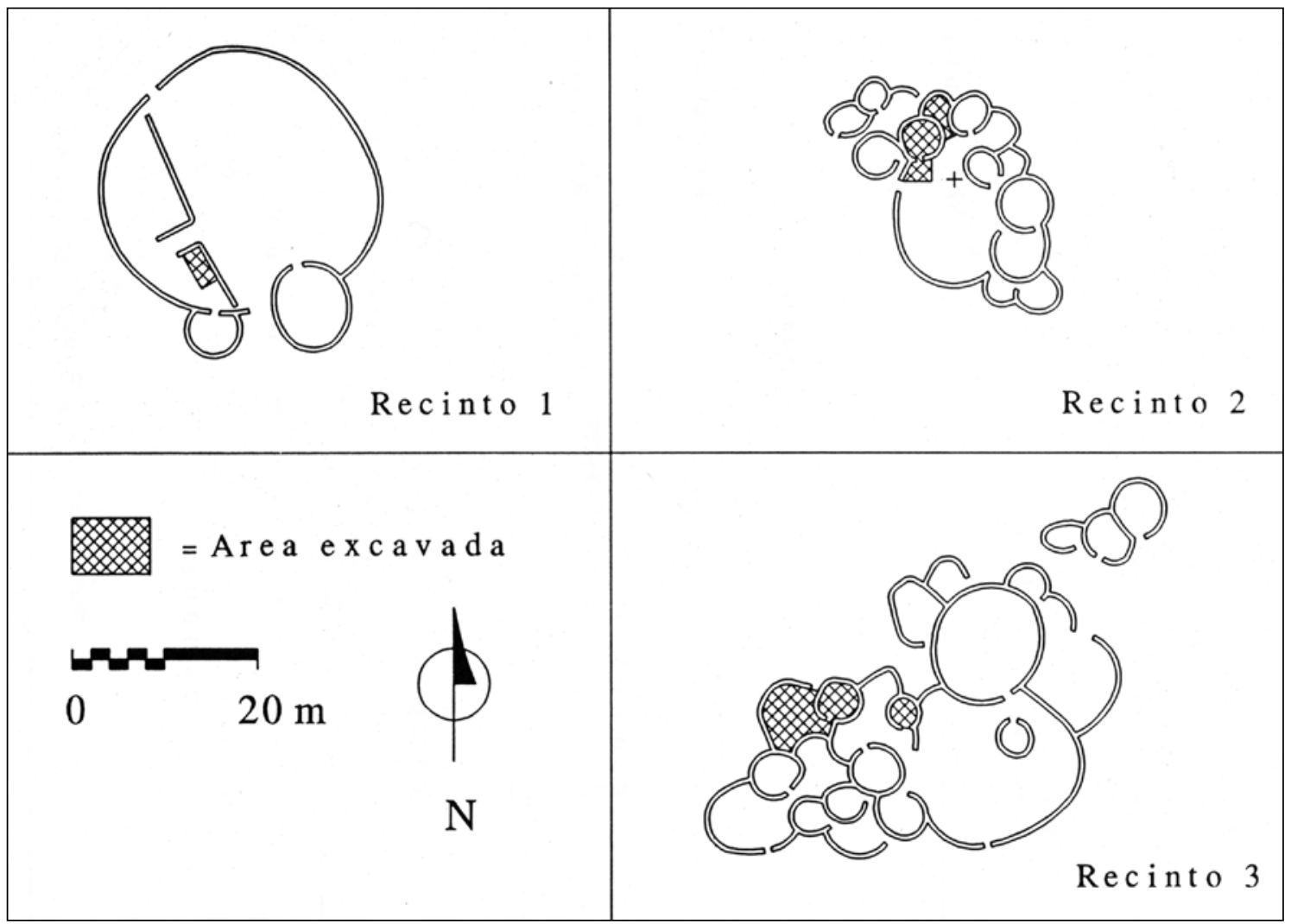

Figura 4. Recintos 1, 2, 3 y las áreas de excavación.

como los minerales de las minas hacia los hornos de Ramaditas, presumiblemente debe haberse realizado con el uso de camélidos.

Los hornos en ruinas, cercanos a Ramaditas y la presencia de otros sitios del Período Formativo Tardío en la quebrada (incluyendo aldeas grandes como G-1 y G-7 en el esquema de Mostny; Figura 2: 2 y 3) puede sugerimos una relación entre esta fundición de metal y el establecimiento de antiguas aldeas en la quebrada. La demostración de la relación, sin embargo, se complica bastante, por cuanto es imposible determinar fechas confiables para los hornos en ruinas, que se ubican en la superficie. Se sabe que el uso de madera antigua para fechar es un problema bastante serio, ya que perfectamente estas fechas pueden señalar un período muy antiguo, cuando en realidad puede ser que la fundición sea de tiempos más modernos. ${ }^{4}$ Por

4 Las evidencias sobre la superficie del sitio mismo nos sugiere que el proceso de fundir cobre en el área siguió desarrollándose después del abandono de este sitio e incluso cuando otros sitios formativos tardíos se instalaron más arriba de la quebrada. Estas evidencias, ubicadas en las ruinas de los hornos de fundición todo esto, es imprescindible contar con una evidencia que sea diferente a los hornos mismos.

Consecuente con lo anteriormente mencionado, se decide buscar la evidencia de metalurgia dentro de las ruinas de la aldea de Ramaditas misma.

sobre el recinto 3, están diseminadas sobre un sector de aproximadamente $4 \times 12 \mathrm{~m}$ entre la plaza y el grupo de estructuras ubicadas más hacia el oeste. Sobre esta superficie se pueden observar, por lo menos, cinco hornos de fundición. En todo este sector no se observan evidencias de restos de sopletes. La data obtenida a partir del carbón que se utilizó en estos hornos entrega una fecha de $2300 \pm 60$ años AP. No obstante, esta fecha debe ser desechada por cuanto con seguridad es propia de un contexto más moderno. En la excavación estratigráfica realizada en el recinto 3, se ubicaron semillas de algarrobo dentro de varios contextos, incluyendo el de antiguas bodegas originales. Este contexto ha sido techado hacia los 2040 \pm 50 años AP (TO-3573. ajustado y calibrado a 50 AC). La interpretación más racional nos dice que después el período de abandono de Ramaditas, esta fundición de cobre siguió funcionando, utilizando para ello a manera de combustible madera del algarrobo de antiguos bosques de la Pampa del Tamarugal. 


\section{Diseño de investigación}

Teniendo en consideración que existen diversos hornos en ruinas en la cercanía del sitio de Ramaditas, se decidió que un esfuerzo importante debía dedicarse a estudiar el rol que habría jugado este sitio en relación a la producción de metal. Bajo esta perspectiva, se planificaron excavaciones para ubicar las respectivas evidencias de este proceso metalúrgico realizado en el sitio.

Consecuente con el problema anterior, se realizaron excavaciones en varios recintos con la idea de descubrir evidencias del proceso metalúrgico. Se llevaron a cabo excavaciones en probables estructuras habitacionales (recinto 2: 22, recinto 3: 57), estructuras como depósitos (recinto 3: 55), pequeñas plazas aglutinadas en torno a las habitaciones (recinto 3: 58), estructuras auxiliares (recinto 2: 22a), y posiblemente espacios públicos y/o habitacionales para élites (recinto 1: 1). Como se observa, el diseño de investigación tuvo como objetivo excavar una variedad de estructuras con el fin de encontrar evidencias metalúrgicas (Figura 5).

Los métodos de excavación y respectiva anotación fueron normales para una acción arqueológica, teniendo en consideración para ello, los procedimientos estratigráficos y obviamente, separando los contextos por rasgos específicos.

Las muestras de trozos de minerales de superficie (19 en total) fueron enviadas al Departamento de Mineralogía del Museo Royal de Ontario (Canadá), con el objeto de realizar análisis de difracción de rayos X. Las muestras de escorias (una de escoria superficial, otra de un bloque de piedra arenisca de un antiguo horno, y finalmente una escoria del contexto perteneciente al Período Formativo Tardío) fueron enviadas al Departamento de Metalurgia y Ciencia de Materiales de la Universidad de Toronto por análisis: dos muestras de la pieza se enviaron al Slowpoke Reactor Facility para hacerle un estudio y análisis de activación neutrónica, el resto del fragmento se envió al Departamento de Metalurgia y Ciencia de Materiales para someterlos a análisis microscópico electrónico de microestructura.

\section{Posición cronológica}

Existen evidencias que indican la construcción del sitio durante el Período Formativo Tardío (Graffam Ms; Martindale Ms).
En primer lugar, hay presencia de artefactos en directa asociación con los pisos entre los cuales existen trozos de cerámicas formativas, figurinas tempranas sin cocción, y puntas pedunculadas típicas de este período.

En segundo lugar, hay un estilo arquitectónico de similares características con la aldea (principal) de Guatacondo, entre estos indicadores sobresalen las estructuras semisubterráneas, el patrón de aglutinamiento, tipos de techo, de entrada, y de ventilación, y el tratamiento de los muros interiores con caras modeladas de arcilla sobre ellos.

Por último, y en tercer lugar, las fechas radiocarbónicas caen en el Período Formativo Tardío, una ubicada en una bodega de un piso original de $2040 \pm 50$ años AP (corregido y calibrado a $50 \mathrm{AC}$; TO-3573), y la otra de un poste vertical del recinto 1 con un resultado de 2040 \pm 60 años AP (corregido; Beta-48822). Estas dos fechas radiocarbónicas del sitio lo ubican en una época más temprana que la que estipula toda la evidencia de la aldea de Guatacondo (en relación a las aceptadas por Meighan 1980).

\section{Problema metalúrgico}

Debemos reconocer que la zona, donde se está trabajando, posee hornos completamente en ruinas, pero que debieran tener directa relación con Ramaditas e incluso con otras aldeas de la quebrada de Guatacondo durante el Período Formativo Tardío. Nuestra responsabilidad, por lo tanto, es demostrar esta conexión. Consecuente con lo anteriormente mencionado, se posee una valiosa evidencia para estos fines, que consiste en una pieza de escoria $\left(1 \mathrm{~cm}^{3}\right)$ que fue encontrada sobre el piso de una estructura (habitación 22) del recinto 2 (Martindale Ms). Esta pieza seguramente puede haber sido dejada en este lugar debido al trabajo que se efectuó sobre el metal de ella -la escoria se encuentra adherida en un lingote- $\mathrm{o}$ bien puede habérsele caído desde las vestimentas a uno de los habitantes de este recinto. El problema en cuestión es el de poder determinar si la escoria representa un valioso indicador como elemento de fundición o como purificación del cobre nativo. Existen otros indicadores más para el efecto de fundición, tales como: los minerales de cobre en algunos recintos excavados, y la evidencia de algunos metales de cobre encontrada sobre el piso original del recinto 1 . No obstante, creemos que el mineral de cobre ubicado ex situ aparte de los hornos puede significar que sea una evidencia de la producción de 


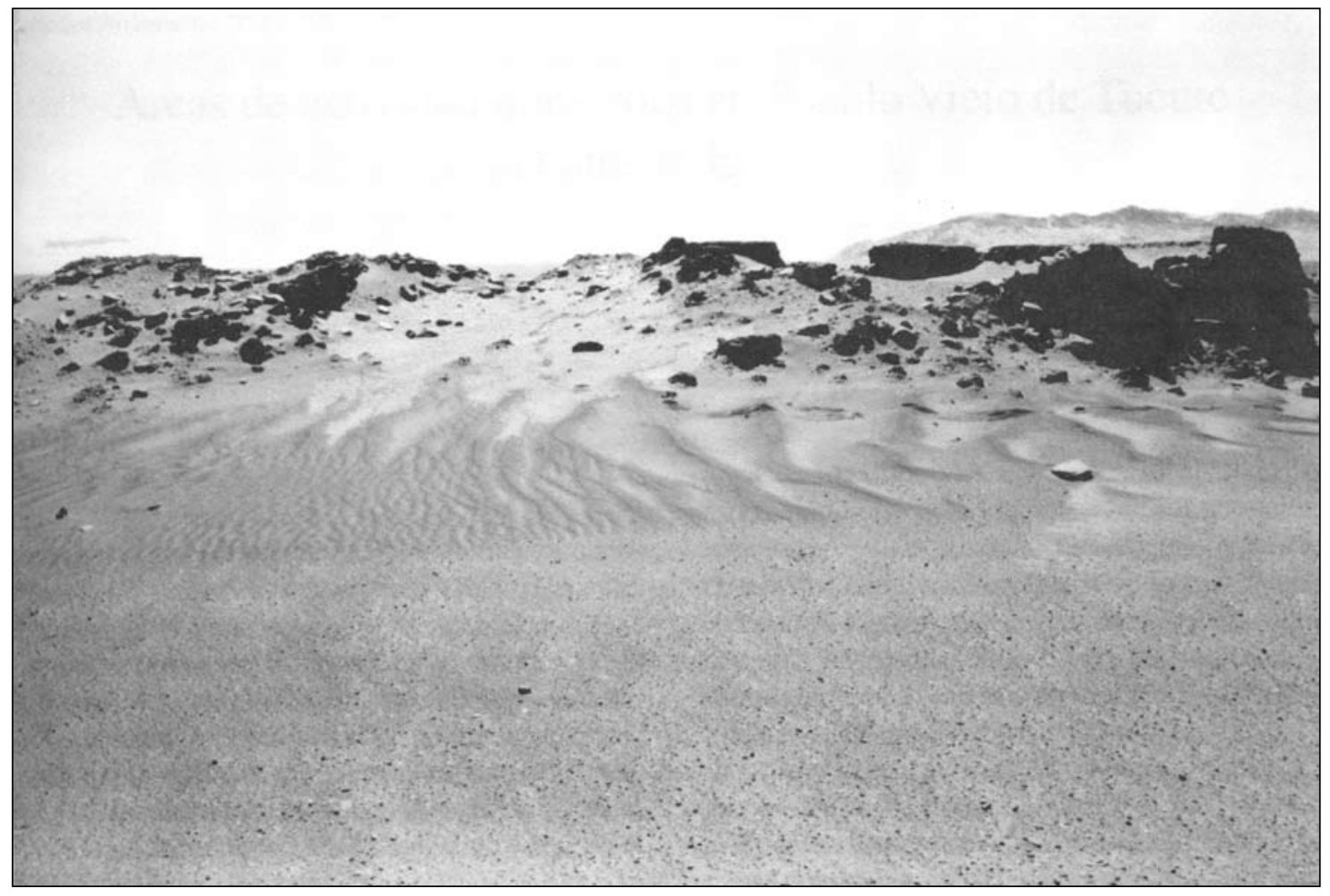

Figura 5. Foto de recinto 1, Ramaditas.

adornos y no de un proceso de fundición de metal en el sitio. Asimismo, el metal de cobre encontrado puede ser también una evidencia de tráfico (si hubiera sido fabricado fuera de la zona del sitio). Basados en estos antecedentes, creemos que para determinar las evidencias efectivas de fundición en el sitio, la muestra de escoria es de vital importancia y más aún la de conocer los análisis efectuados a ella.

\section{Análisis metalúrgico}

Los análisis de escorias se presentan en la Tabla 1. Los elementos metálicos son conocidos como "óxidos de metales", que es usual en el análisis de fluorescencia de rayos X; también se presenta el contenido de cobre metálico dentro de la escoria.

Realizados los análisis respectivos se demuestra claramente que:

1) La escoria tiene cobre y otros elementos propios de un proceso de fundición de cobre (Rehder Ms).

2) La escoria es propia de una fundición de cobre con un bajo contenido de cobre metálico $(0.9 \%)$, lo que señala muy claramente un proceso de fundición,

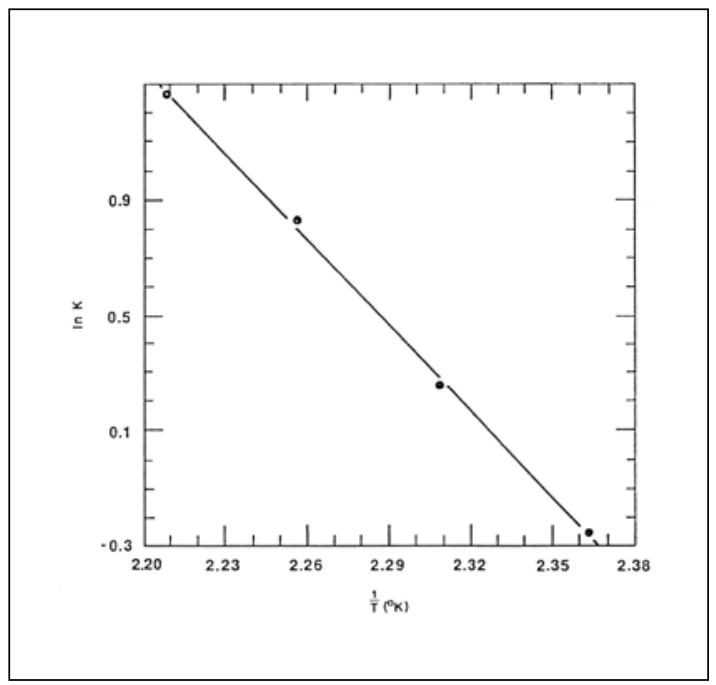

Figura 6.

pero no de refinamiento de cobre nativo (Franklin com. pers.). Esta interpretación se sostiene por el mismo perfil que presentan los análisis de la escoria antigua (A) (del piso original, recinto 2) y las escorias asociadas a los hornos destruidos de la superficie (B) (ver Tabla 1). 


\begin{tabular}{|l|c|c|}
\cline { 2 - 3 } \multicolumn{1}{c|}{} & Slag A & Slag B \\
\hline $\mathrm{Al}_{2} \mathrm{O}_{3}$ & 18.7 & 14.4 \\
\hline $\mathrm{CaO}$ & 3.0 & 9.3 \\
\hline $\mathrm{Cu}_{2} \mathrm{O}$ & 1.0 & 2.3 \\
\hline $\mathrm{FeO}$ & 4.1 & 3.8 \\
\hline $\mathrm{K}_{2} \mathrm{O}$ & 1.3 & 3.3 \\
\hline $\mathrm{MgO}$ & 2.0 & 2.0 \\
\hline $\mathrm{MnO}$ & 0.2 & 0.0 \\
\hline $\mathrm{Na}_{2} \mathrm{O}$ & 3.1 & 3.3 \\
\hline $\mathrm{P}_{2} \mathrm{O}_{5}$ & 1.2 & 0.4 \\
\hline $\mathrm{PbO}^{\circ}$ & 0.6 & 0.0 \\
\hline $\mathrm{SiO}_{2}$ & 61.2 & 60.0 \\
\hline $\mathrm{TiO}_{2}$ & 0.2 & 0.4 \\
\hline Total & $96.6 \%$ & $99.0 \%$ \\
\hline $\mathrm{Temp}$ de fluidez & $1250^{\circ} \mathrm{C}$ & $1250^{\circ} \mathrm{C}$ \\
\hline $\mathrm{Cobre}$ metálico & $0.9 \%$ & $2.0 \%$ \\
\hline
\end{tabular}

Tabla 1. Análisis de escorias por fluorescencia de rayos X.

En síntesis y de acuerdo a los análisis efectuados en las escorias, se puede determinar que los pobladores de Ramaditas tuvieron una importante actividad en la fundición de cobre cerca 50 AC. El análisis de la muestra de metal nos demuestra que la población de Ramaditas manufacturó cobre por fundición, como un procedimiento de producción absolutamente legítimo.

Esta muestra de metal de cobre (del piso original, recinto 1 ), de acuerdo a la Tabla 2 , en una primera instancia se aprecia como un objeto de alta pureza de cobre $(99.5 \%)$ pasando a considerarse como cobre nativo, pero el bajo contenido de oro y plata hizo dudar su característica de ese cobre. Esta duda por saber si la muestra de metal era de cobre nativo o fundido fue dilucidada por un análisis microscópico electrónico de una sección de metal (Neub Ms). En este análisis se observó que en el metal existían nódulos de óxidos de cobre (3-5 micrones, 2-4\% por vol.) (Figura 6). Este indicador permitió sin dudas concluir que el análisis corresponde a una fundición de cobre, y no a un cobre nativo, por cuanto el óxido de cobre no existe en este tipo de metal (Rehder Ms; Franklin com. pers.).

El tipo de mineral que se seleccionaba para esta fundición es probablemente el mineral sulfuroso. Sobre la superficie, junto a los hornos cerca de Ramaditas, se encontraron dos tipos de minerales

\begin{tabular}{|l|c|c|c|}
\hline Elemento raro & Sigla & Muestra 1 & Muestra 2 \\
\hline antimonio & $\mathrm{Sb}$ & $\leq 0.43$ & $\leq 0.19$ \\
\hline arsénico & $\mathrm{As}$ & $\leq 2.9$ & 240 \\
\hline bromo & $\mathrm{Br}$ & 7.9 & 7.8 \\
\hline cadmio & $\mathrm{Cd}$ & $\leq 29$ & $\leq 9$ \\
\hline cinc & $\mathrm{Zn}$ & $\leq 41$ & $\leq 40$ \\
\hline cobalto & $\mathrm{Co}$ & 4.3 & 8.4 \\
\hline cromo & $\mathrm{Cr}$ & $\leq 14$ & $\leq 13$ \\
\hline escandio & $\mathrm{Sc}$ & 0.18 & 0.06 \\
\hline estaño & $\mathrm{Sn}$ & $\leq 270$ & $\leq 240$ \\
\hline hierro & $\mathrm{Fe}$ & $\leq 540$ & $\leq 640$ \\
\hline indio & $\mathrm{In}$ & $\leq 1.6$ & $\leq 1.2$ \\
\hline lantano & $\mathrm{La}$ & $\leq 1.6$ & $\leq 1.6$ \\
\hline manganeso & $\mathrm{Mn}$ & 23 & 20 \\
\hline mercurio & $\mathrm{Hg}$ & 14 & 11 \\
\hline níquel & $\mathrm{Ni}$ & $\leq 100$ & $\leq 100$ \\
\hline oro & $\mathrm{Au}$ & 0.099 & 0.090 \\
\hline samario & $\mathrm{Sm}$ & $\leq 0.22$ & $\leq 0.2$ \\
\hline selenio & $\mathrm{Se}$ & $\leq 14$ & $\leq 13$ \\
\hline sodio & $\mathrm{Na}$ & 1000 & 970 \\
\hline plata & $\mathrm{Ag}$ & 560 & 600 \\
\hline torio & $\mathrm{Th}$ & $\leq 0.91$ & $\leq 0.81$ \\
\hline \multicolumn{1}{|c|}{ Total } & & $\mathbf{0 . 2 6 \%}$ & $\mathbf{0 . 2 9 \%}$ \\
\hline
\end{tabular}

Tabla 2. Análisis de la hoja de cobre vía activación neutrónica (ppm).

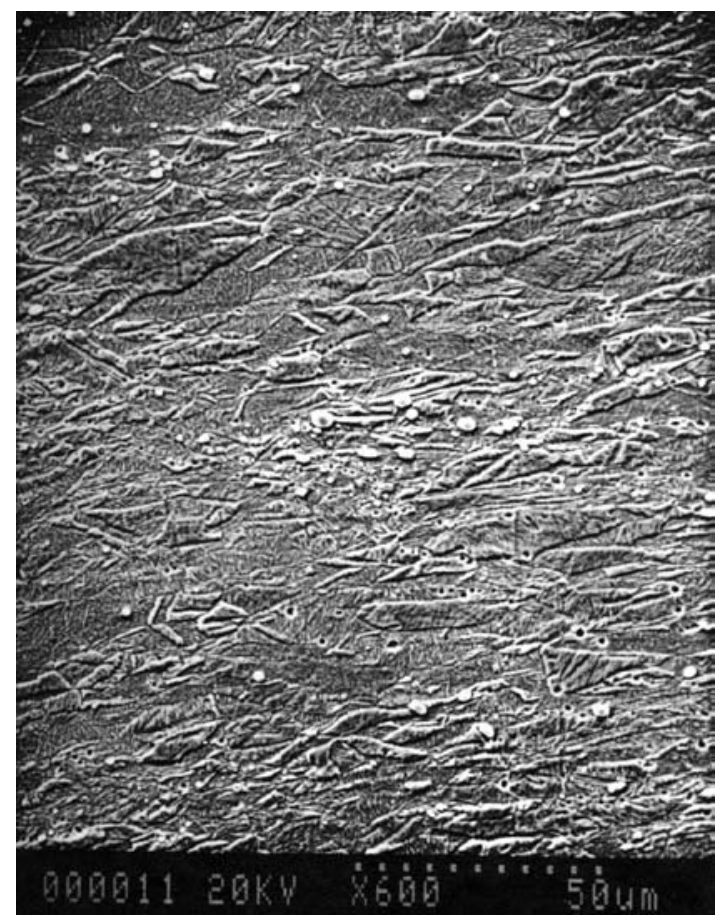

Figura 6. Foto por microscopio electrónico de una sección de metal de Ramaditas. 
muy característicos de la zona y del norte chileno, como son la brochantite $\left(\mathrm{CuSO}_{4} * 3 \mathrm{Cu}(\mathrm{OH})_{2}\right)$ y anterlite $\left(\mathrm{CuSo}_{4} * 2 \mathrm{Cu}(\mathrm{Oh})_{2}\right)(\mathrm{Back} \mathrm{Ms})$. El primero se encuentra en antiguos contextos altiplánicos (Browman 1991). Estos tipos de materiales se supone fueron utilizados durante la ocupación original del sitio. La escoria es el producto del fluido de los minerales en combinación con los agentes de flujo utilizados en el proceso de fundición, de allí entonces que la similitud entre la antigua escoria y las de superficie permiten plantear la idea que los mismos cuerpos de minerales sulfurosos posiblemente fueron seleccionados durante el Período Formativo Tardío, siendo utilizados aun en épocas posteriores. Esta observación es bien importante, ya que se sabe que los minerales sulfurosos son más difíciles de fundir, necesitando previamente la remoción del azufre, de manera tal que al proceso de fundición lo hace más complejo en comparación con otros métodos, lo que también indica que esta fundición de metal debió comenzar en esta zona antes de ese período, cuando seguramente se utilizaban otros métodos menos complejos (Graffam Ms).

\section{Problemas para investigaciones futuras}

Los resultados entregados con anterioridad señalan claramente que la fundición de cobre de Ramaditas (en la vecindad inmediata) tuvo su funcionamiento durante el Período Formativo Tardío. Sin embargo, los mismos datos también nos demuestran que existe una escasa evidencia de metalurgia en los sitios habitacionales de este mismo período, lo que sin duda representa un serio problema de investigación, dada la imposibilidad de fechar directamente los hornos cerca de los sitios, pero aparte de contextos sellados arqueológicamente. Consecuente con esta situación, en adelante se detallan algunos puntos importantes de abordar en la investigación futura de este tema.

Debe tenerse en consideración que excavaciones futuras en sitios de este período deben incluir el estudio de la antigua metalurgia, dado que las evidencias en esta temática son muy escasas. En particular, la escoria debe ser buscada prolijamente, ya que es una evidencia que puede pasar fácilmente inadvertida, y de este modo perder una valiosa evidencia de la producción metálica. Debe destacarse que para ello no debe obviarse el encontrar aunque sea uno o dos trozos de escoria en algún recinto, ya que ellos pueden ser útiles para el estudio propuesto.
Una de las interrogantes del sitio de Ramaditas es la escala de producción y el trabajo, tanto en el sitio como en las áreas adyacentes al mismo. Este estudio es bastante difícil de determinar, pero si se logra extrapolar la escala general de producción por la evidencia de objetos encontrados en contextos funerarios del período podrían existir evidencias concretas al respecto. En todo caso, va a ser muy difícil saber el nivel de producción, mientras no sea posible hacer una relación de objetos, por ejemplo, entre la costa y el altiplano y el área de producción de Ramaditas.

Otra de las interrogantes del sitio es qué tipos de objetos fueron hechos allá. No se encuentran los artefactos mismos en la excavación del sitio, los que debieron ser enterrados con la población del sitio si no fueron refundidos o distribuidos a otras partes, pero podemos apreciar que los artefactos probablemente incluidos los artículos de joyería, como el pendiente del cementerio de la aldea de Guatacondo (excavado por P. Núñez en 1969), cerca del sitio y fechado inmediatamente después de la ocupación de Ramaditas.

Otro problema importante de abordar es el relativo al origen de los objetos metálicos y su directa relación con las áreas de producción. Este problema es bastante complejo, por cuanto los metales fabricados en diferentes lugares pueden haber sido refundidos e inutilizados, mezclándose sus elementos químicos, de modo que se haría difícil identificar cuál es de un lugar y cuál de otro. Sin embargo, probablemente los no reutilizados, tales como: placas, anillos, pectorales $\mathrm{u}$ otros objetos de joyería, que se encontraron en contextos funerarios, los cuales tienen una matriz química homogénea y pueden presentar un análisis más confiable. ${ }^{5}$

Una de las tareas más importantes en el futuro de esta investigación es la de saber cómo se puede separar el cobre fundido del cobre nativo mediante análisis metalúrgicos confiables a través de no más de la pequeña muestra que se requirió para Ramaditas. Lo que sí se hace necesario ahora es una investigación sistemática de muestras de cobre nativo y cobre fundido prehispánico en la región,

5 Para el caso de Ramaditas existe actualmente poco metal para investigar este tema, no obstante, los resultados presentados por lo menos otorgan una pista acerca del metal fabricado en este sitio, mediante el análisis de activación neutrónica efectuado en los elementos raros. 
con el objeto de saber si realmente es posible separar uno de otro cobre. Los datos de estudio pueden ser utilizados positivamente para saber cuándo y en qué lugar comenzó el acceso al cobre fundido, como asimismo para comprender hasta cuándo se utilizó y se mantuvo el cobre nativo en la región.

\section{Discusión y conclusión}

Podemos concluir que el proceso de fundición de Ramaditas fue mucho más eficiente que el efectuado en la fundición de Batán Grande de Perú, en épocas más tardías (Shimada et al. 1982, 1983). Esta eficiencia queda demostrada por el hecho de que la temperatura empleada en Ramaditas fue más alta (cercana a los $1250{ }^{\circ} \mathrm{C}$ ), lo que permitió la separación efectiva entre la escoria y el metal (Graffam Ms; Rehder Ms); no sucediendo lo mismo en Batán Grande donde tenían que llevarse a cabo cuatro pasos para su separación efectiva. En Batán Grande: 1) Fundición de prills, como trozos metálicos (en estado acuoso) dentro de la escoria viscosa; 2) Golpeado de la escoria para extraer los prills (trozos de metal); 3) La separación a mano del metal de la escoria, y 4) La cocción (como refundición) en crisoles de los prills, para manufacturar lingotes de metal.

La diferencia entre estos procesos de fundición estaría dada por el uso de las corrientes de aire natural en Ramaditas, y el uso de sopletes en Batán Grande. En este último caso, el contenido de oxígeno es menor y la humedad es más alta por el aliento humano, esto produce que la temperatura sea más baja en relación con la producida por corriente de aire natural (Rehder Ms). En Ramaditas, y específicamente en las ruinas de los hornos de la zona, no se encontró ninguna evidencia de sopletes, lo que sugiere que el modo de fundición de este sitio y en esta zona fue del tipo corriente de aire natural.

La temática de la fundición de metales en el Norte Grande de Chile se desenvolvió seguramente dentro de un sistema de relaciones comerciales de tráfico de gran alcance y desarrollo en un patrón de asentamiento regional muy disperso. De allí entonces que las evidencias de fundición durante este Período Formativo Tardío demostraron ser muy diferentes al proceso conocido en otros lugares y otros períodos, tal como sucede con los centros especializados de Batán Grande en Perú y Viña del Cerro en Chile (Shimada et al. 1982, 1983; Niemeyer et al. 1983).
El sitio de Ramaditas es una pequeña aldea cuyas evidencias todavía no pueden darnos la solución a todos los problemas planteados para ella. No obstante lo anterior, las pocas evidencias han sido estudiadas con bastantes detalles y rigurosidad científica, lo que ha permitido comprender algunos importantes aspectos de la producción metalúrgica del período en cuestión que antes de este estudio no se conocían. Las evidencias del sitio demuestran claramente que la fundición de minerales fue una actividad realizada a los 50 años $\mathrm{AC}$ en el desierto chileno. Este sitio permite sostener la primera evidencia directa de que la metalurgia de cobre (supongamos también otros metales) permitió un desarrollo económico dentro de una red de intercambio entre la costa y el altiplano durante el Período Formativo Tardío. Asimismo entrega valiosos antecedentes para los modelos de sustentación económica y cultural en los Andes Centro Sur, especialmente sobre temas metalúrgicos (Barón y Serracino 1980; Núñez 1987). Por todo lo anterior, los resultados de este sitio pueden ser bastante significativos.

Claramente se desprende de los resultados anteriormente mencionados, que el proceso metalúrgico de este sitio incluyó la fundición de minerales sulfatados como brochantita y antlerita. Por otra parte, la investigación de las escorias demuestra que ellas son parte de biproductos fundidos, lo que señala un claro proceso de reducción de minerales, no de refinamiento del metal. Esto último se demuestra por la composición de las escorias. Las que en superficie se hallaron en asociación con trocitos de cobre que son características de una fundición. La temperatura aproximada utilizada en los antiguos hornos, como es indicado por los análisis de las escorias, fue de $1250{ }^{\circ} \mathrm{C}$, lo que se apoya también por las evidencias visuales de ellas. Esta temperatura fue más que suficiente para poder separar el metal de la escoria. Esta observación es muy importante, porque significa que la separación no se hizo a mano como lo sucedido en Batán Grande en Perú. Por último, podemos decir que la presencia en el sitio de metal de cobre en forma de láminas fue probablemente trabajado en este mismo lugar.

Podemos concluir que durante el Período Formativo Tardío los habitantes de las pequeñas aldeas del desierto chileno manufacturaban metalurgia con un sistema viable y eficiente. Esta interpretación concuerda con numerosas evidencias de artefactos de cobre encontrados en sitios de la región, especialmente al sur de la quebrada de Tarapacá hacia San 
Pedro de Atacama. Estas aldeas proporcionaron a través de la fundición de metales una producción y fabricación de objetos varios dentro de un contexto más amplio de explotación de recursos y comercio interregional, que tuvo por objeto conectar tierras altas, el desierto y la costera.

Agradecimientos El proyecto se llevó a cabo gracias a los fondos proporcionados por: Consejo de Investigación en Ciencias Sociales y Humanidades "SSHRC" (Canadá), Universidad Trent (Canadá), Cominco Ltda. (Canadá), Cominco Recursos Internacionales (Canadá), y la Corporación Teck (Canadá). El proyecto también se ha beneficiado con la ayuda de las colegas canadienses:
J. E. Rehder (Universidad de Toronto), Ursula Franklin (Universidad de Toronto), John Topic (Universidad Trent), Theresa Topic (Universidad Trent), Ron Hancock (Universidad de Toronto), Joseph Mandarino (Museo Royal de Ontario), Malcolm Back (Museo Royal de Ontario), Larry Pavlish (Universidad de Toronto), Ered Neub (Universidad de Toronto), Mark Ward (Universidad de Toronto). Se agradece la ayuda de Andrew Martindale, Craig Bissell, y Emily Stovel, por su trabajo en terreno durante 1992. Finalmente, se agradece también al personal del Museo de la Universidad Arturo Prat (Iquique, Chile), y al Departamento de Metalurgia y Ciencia de Materiales, Universidad de Toronto (Canadá).

\section{REFERENCIAS CITADAS}

ALVAREZ, L., 1981. Metalurgia prehispánica en el extremo norte de Chile. Revista Fariña 1: 33-38.

BACK, M., 1993Ms. Result of x-ray powder diffraction analyses of copper ores from the Ramaditas site, Northern Chile. Technical report on file, Trent University.

BARON, A. M. y G. SERRACINO, 1980. Rol social de los metales en San Pedro de Atacama. VI Congreso Nacional de Arqueología.

BENSON, E., 1979. Pre-Columbian metallurgy of South America. Dumbarton Oaks, Washington D. C.

BOMAN, E., 1908. Antiquités de la Région Andine de la République Argentine et du Désert d'Atacama. Imprimerie Nationale, París.

BROWMAN, D. L., 1991. The dynamics of the Chiripa polity. Ponencia presentada en el $47^{\circ}$ Congreso Internacional de Americanistas, Nueva Orleans.

CASTILLO, G., 1986. Sociedades agropecuarias tempranas y control de recursos en el ambiente semiárido de Chile. Chungara 16-17: 173-180.

DAUELSBERG, P., 1985. Faldas del Morro: Fase cultural agroalfarera temprana. Chungara 14: 7-44.

DILLEHAY, T. y L. NUÑEZ, 1988. Camelids, caravans, and complex societies in the South-Central Andes. Recent studies in Pre-Columbian archaeology, N. J. Saunders y O. de Montmollin, (Eds.), pp. 603-634. BAR International Series 421 II, Oxford.

DRANSART, P., 1991. Llamas, herders and the exploitation of raw materials in the Atacama. World Archaeology 22 (3): 304-319.

GONZALEZ, A. R., 1992. Las placas metálicas de los Andes del Sur. Verlagphillipp von Zabern.

1979 Pre-Columbian metallurgy of Northwest Argentina: Historical development and cultural process. En Pre-Columbian metallurgy of South America, E. Benson (Ed.), pp. 133-202. Dumbarton Oaks, Washington D. C.

GRAFFAM, G., 1993Ms. Metallurgical observations from the Ramaditas site, Atacama Desert, Northern Chile. Trent University.

HANCOCK, R., 1993Ms. Instrumental neutron activation analysis of metal from the Ramaditas site, Atacama Desert, Northern Chile. Trent University.

IRIBARREN, J., 1974Ms. La metalurgia en Chile en la época precolombina. Ponencia presentada en el $2^{\circ}$ Congreso Peruano del Hombre y la Cultura Andinos, Trujillo.

KJERRMANN, B., 1944. Analytical report of an ancient copper spade from Chiu Chiu in Northern Chile. Contributions to the archaeology of the rio Loa Región, S. Rydén (Ed.), pp. 242-250. Elanders Boletryckeri Aktiebolag, Gotemburgo.

LATCHAM, R., 1936. Metalurgia atacameña. Boletín del Museo Nacional 15: 107-151.

LECHTMAN, H., 1986. Perspectives on the pre-Columbian metallurgy of the Americas. En Metalurgia de América precolombina, C. Plazas (Ed.), pp. 20-36. $45^{\circ}$ Congreso Internacional de Americanistas, Bogotá.

1980. The Central Andes: Metallurgy without iron. En The corning of the Age of Iron, T. A. Wertime y J. D. Muhly (Eds.), pp. 269-334. Yale University Press, New Haven.

1979. Issues in Andean metallurgy. En Pre-Columbian metallurgy of South America, E. Benson (Ed.), pp. 1-40. Dumbarton Oaks, Washington D. C.

1976. A metallurgical site survey in the Peruvian Andes. Journal of Field Archaeology: 1-42.

MARTINDALE, A., 1993Ms. Excavations at compound 2, Ramaditas site, Northern Chile. Technical report on file, Trent University. 
MAYER, E., 1986. Armas y herramientas de metal prehispánicas en Argentina y Chile. AVA Materialien Band 18, Bonn.

MEIGHAN, C., 1980. Archaeology of Guatacondo, Chile. En Prehistoric trails of Atacama, C. Meighan y D. True (Eds.), pp. 99-126. Monumenta Archaeologica 7. University of California, Los Angeles.

MOSTNY, G., 1980. The archaeological zone of Guatacondo. En Prehistoric trails of Atacama, C. Meighan y D. True (Eds.), pp. 91-97. Monumenta Archaeologica 7, University of California, Los Angeles.

1970. La subárea arqueológica de Guatacondo. Boletín del Museo Nacional de Historia Natural 29: 271-287.

MUÑOZ, I., 1989. El Período Formativo en el Norte Grande (1000 $\mathrm{AC}$ a 500 DC). En Culturas de Chile. Prehistoria. Desde sus orígenes hasta los albores de la Conquista, J. Hidalgo, V. Schiappacasse, H. Niemeyer, C. Aldunate e I. Solimano (Eds.), pp. 107-128. Editorial Andrés Bello, Santiago.

1986. Aportes a la reconstitución histórica del poblamiento aldeano en el valle de Azapa (Arica, Chile). Chungara 16-17: 307-322.

NEUB, F., 1993Ms. SEM analyses of metal from Ramaditas, northern Chile. Technical report on file, Trent University.

NIEMEYER, H., G. CASTILLO, M. CERVELLINO, 1989. Los primeros ceramistas del Norte Chico: Complejo Molle (0 a 800 DC). En Culturas de Chile. Prehistoria. Desde sus orígenes hasta los albores de la Conquista, J. Hidalgo, V. Schiappacasse, H. Niemeyer, C. Aldunate e I. Solimano (Eds.), pp. 227-263. Editorial Andrés Bello, Santiago.

NIEMEYER, H., M. CERVELLINO y E. MUÑOZ, 1983. Viña del Cerro: Expresión metalúrgica inca en el valle de Copiapó. Creces 4 (4): 32-35.

NORDENSKIÖLD, E., 1921. The Copper and Bronze Ages in South America. Comparative ethnographical studies, vol. 4. Pehrssons Föflag, Gotemburgo.

NUÑEZ L., 1989. Hacia la producción de alimentos y la vida sedentaria (5.000 AC a $900 \mathrm{AC})$. En Culturas de Chile. Prehistoria. Desde sus orígenes hasta los albores de la Conquista, J. Hidalgo, V. Schiappacasse, H. Niemeyer, C. Aldunate e I. Solimano (Eds.), pp. 81-105. Editorial Andrés Bello, Santiago.

1987. Tráfico de metales en el Area Centro Sur Andina: Factos y expectativas. Cuadernos del Instituto Nacional de Antropología: 73-105.
_ 1982. Temprana emergencia de sedentarismo en el desierto chileno: Proyecto Caserones. Chungara 9: 80-123.

NUÑEZ, L. y T. DILLEHAY, 1979. Movilidad giratoria, armonía social y desarrollo en los Andes Meridionales: Patrones de tráfico e interacción económica (ensayo). Universidad Católica del Norte, Antofagasta.

NUÑEZ, L. y C. MORAGAS, 1977. Ocupación con cerámica temprana en la secuencia del Distrito de Cáñamo (costa desértica del norte de Chile). Estudios Atacameños 5: 21-49.

NUÑEZ, L., V. ZLATAR, y P. NUÑEZ, 1975. Relaciones prehistóricas trasandinas entre el Noroeste Argentino y el norte chileno (Período Cerámico). Estudios Atacameños 5: 21-49.

PEDERSEN, A., 1971. Aspectos de la metalurgia indígena americana prehispánica: La huayra y su empleo en el proceso de fundición. Etnia 14.

PETERSEN, G., 1970. Minería y metalurgia en el Perú. Arqueológicas 12.

REHDER, J. E. 1993Ms. Metallurgical materials from Ramaditas, Chile. Technical report on file, Trent University.

RIVERA, M., 1991. Prehistory of Northern Chile: A synthesis. Journal of World Prehistory 5 (1): 1-47.

1976. Nuevos aportes sobre el desarrollo cultural prehispánico en los valles bajos del extremo norte de Chile, durante el Período Intermedio Temprano. En Homenaje al Dr. Gustavo Le Paige s. j. Universidad Católica del Norte, Antofagasta.

RIVERA, M., P. SOTO, L. ULLOA, y D. KUSHNER, 1974. Aspectos sobre el desarrollo tecnológico en el proceso de agriculturación en el norte prehispánico, especialmente Arica (Chile). Chungara 3: 79-107.

RODRIGUEZ, L., 1986. Pre-Columbian metallurgy of the Southern Andes: A regional synthesis. En Pre-Columbian metallurgy, pp. 402-417. Banco de la República, Bogotá.

SANTORO, C., 1982. Formativo Temprano en el extremo norte de Chile. Chungara 8: 33-62.

SHIMADA, I., M. STEPHEN, A. EPSTEIN y A. CRAIG, 1982. Batán Grande: A prehistoric metallurgical center in Perú. Science 216: 952-959.

1983. The metallurgical process in Ancient north Peru. Archaeology 36 (5): 38-45. 